Journal of Neuroimaging in Psychiatry \& Neurology

\title{
Acknowledgement of Manuscript Reviewers JNPN Volume-5 (2020)
}

The Editors of Journal of Neuroimaging in Psychiatry and Neurology (JNPN) would like to express their tremendous gratitude to all those individuals who participated in the peer review process during the preparation of this Volume-5 (2020). Many reviewers from around the world and across various disciplines provided their expert input that led to publication of the articles. The peer reviewer's generosity, judicious judgment, and timely response substantially helped us to publish a journal that both is timely and maintains scientific standards; it is a genuine pleasure to express our deep sense of thank to all the reviewers collectively for their dedicated service.

List of Reviewers for Volume 5 (2020)

Neena Baby
Dimpi Sinha
Anita Khanna Mehta
Tulupov Andrey
Aliye Tosun
Patrick T. Ronaldson
Ulrich Hegerl
Liemei Guo
John A Buford

Zong-Hui Liang

Alvin Das

Xiaojuan Wang

Aleksandrovich

Gülin Öz

Fleur M. Howells

Stefania Marzocco

Jan Fritz

Rezakova Mariya

Received: January 12, $2021 \quad$ Accepted: January 13, $2021 \quad$ Published: January 16, 2021

Citation: Acknowledgement of Manuscript Reviewers JNPN Volume-5 (2020). J Neuroimaging Psychiatry Neurol 5(2): 29.

Copyright: (c) 2021 This is an Open Access article distributed under the terms of the Creative Commons Attribution 4.0 International License (CCBY) (http://creativecommons.org/licenses/by/4.0/) which permits commercial use, including reproduction, adaptation, and distribution of the article provided the original author and source are credited.

Published by United Scientific Group 